\title{
Effects of temperature on oocyte growth in the Mediterranean terebellid
}

\section{Eupolymnia nebulosa (Annelida, Polychaeta)}

\author{
J.-H. Cha (1)(2), D. Martin (1)(3) and M. Bhaud (1)
}

(1) Observatoire Océanologique, Laboratoire Arago. Université P. et M. Curie, C.N.R.S. (U.R.A. 117). F-66650 Banyuls-sur-Mer. France. Fax. 3368887395

(2) KORDI (Korean Ocean Research and Developments Institute). Biological Oceanography Division. Ansan P.O. Box 29. Seoul. South Korea. Fax. 823454085820

(3) Contact address: Centre d'Estudis Avançats de Blanes (C.S.I.C.). Camí de Santa Bàrbara s/n, 17300-Blanes (Girona), Spain.Fax.34 723378 06.E-mail.dani@ceab.csic.es

\begin{abstract}
Eupolymnia nebulosa (Montagu) is a widely distributed terebellid polychaete. It builds its tubes in the coastal shelf, always in areas with mixed soft and hard bottoms. From a long-term survey carried out in the Bay of Banyuls, France (NW Mediterranean), the coincidence of an advancement of the spawning period with a delay of the thermocline breakdown has been pointed out. We postulate that a persistent high temperature could act on gamete development by stimulating oocyte growth, subsequently causing the advancement of cocoon release. During 1992 and 1993, we have used a between-individuals experimental approach based on: (1) the use of oocyte "net" growth; (2) the identification of differences in oocyte growth rate among females; (3) the determination of non significantly different pairs of "net" oocyte size distributions at the beginning of the experiment to compare them at the end. The effect of temperature on oocyte growth was not detected at a population level. However, a positive individual response to the maintenance of a high temperature has been demonstrated. Thus, the lack of a significant response by the population does not imply the absence of any response by individuals. We also propose a model of oocyte growth dynamics interacting with temperature. The model is based on our experimental results, but also on the following previous observations: (1) the occupation by oogenesis and oocyte growth of periods of both rising and declining temperature; and (2) the dispersed appearance of oocyte size distributions at the onset of the spawning period.
\end{abstract}




\section{Introduction}

Life cycles are the product of a series of long-term, continuing interactions between environmental and biological processes (Olive 1980; see Bentley and Pacey 1992 for a review). The source of year to year variability in recruitment and reproductive cycles appears to be a consequence of the interplay between two categories of determinism which can be related to two different approaches (Bhaud et al. 1995): (1) Evolutionary biology, which addresses ultimate causes such as the specific adjustment of biological events superimposed on the climatic calendar. (2) Functional biology, which addresses proximate causes and deals with a physiological function on a short term scale - such as oocyte growth linked with temperature - and which lead to disturbances in the preceding adjustment.

Many invertebrates show marked annual reproductive periodicity which is an evolutionary stable response maintained by short term responses to environmental variables. When the observed patterns are correlated with the considered variables (including temperature), a cause effect relationship is usually identified, in spite of the fact that correlation does not necessarily imply causation (Boero et al. 1996). Moreover, such an observed correlation does not on its own establish what are the physiologically important factors maintaining the observed cycle (Olive 1980, 1992). Thus, in addition to an endogenous regulation, there must also be an input/transduction process allowing the organisms to respond to exogenous information (Barnes 1975; Olive et al. 1990). However, the mechanisms involved are usually poorly understood (the black box organism in Giese 1959).

The effects of temperature on invertebrates have been extensively studied (Precth et al. 1973). However, there is, to some extent, a lack of experimental demonstration of the effects of environmental changes on a physiological process like gamete growth (but see Pearse 1990 's paper for an experimental approach to the effects of photoperiod). From a long-term survey on the life cycle of Eupolymnia nebulosa (Montagu) - a tube building terebellid polychaete - carried out in the French Catalan coasts (Bay of Banyuls, North Western Mediterranean Sea), certain relationships between changes in the annual pattern of temperature and the development of the reproductive cycle have been identified. For instance, the coincidence of an advancement of the spawning period with a delay of the thermocline breakdown has been pointed out (Bhaud et al. 1994). This phenomenon may be of importance for $\underline{E}$. nebulosa population dynamics because of the switch from planktonic to benthic larvae 
in relation to the increase of temperature during the spawning period (Duchêne and Nozais 1992).

Eupolymnia nebulosa builds its tubes in the coastal shelf, always in areas with mixed soft and hard bottoms. In the Bay of Banyuls, field populations of E. nebulosa commence oocyte growth during autumn (Fig. 1), when the temperature declines but the thermocline is still maintained (Bhaud and Grémare 1991). The species has a very complicated reproductive cycle which is clearly reflected by the spawning features: (1) oogenesis extending up to, and probably through, the spawning period; (2) spawning period extending from March to May; (3) up to 5 highly synchronized peaks of egg-mass production at a population level ; and (4) from 1 to 4 egg-masses per female and spawning period (personal observations; Bhaud and Grémare 1991; Grémare 1988; Duchêne and Nozais 1992). The early production of eggmasses has been associated with(to) the release of planktonic larvae (Duchêne and Nozais 1992). This implied: (1) an increase of the effects of dispersion-related processes (i.e., colonization of new substrata, genetic exchange); and (2) a negative effect on the subsequent success of larval benthic recruitment to a substratum suitable for adult populations (which is located in a narrow belt extending from 1 to $10 \mathrm{~m}$ depth in the studied area). On the other hand, egg-masses produced latter during the spawning period give rise to large, benthic larvae which immediately settle in(to) the original habitat.

In this study, we have adopted a between-individuals experimental approach to test the hypothesis that a persistent high temperature could act on gamete development of Eupolymnia nebulosa by stimulating oocyte growth, subsequently increasing the number of oocytes ready to be released at the beginning of the spawning period. Furthermore, we propose a model of oocyte growth dynamics interacting with temperature, and we discuss some aspects related to the spawning mechanism in E. nebulosa.

\section{Material and methods}

We performed two sets of experiments in 1992 and 1993, respectively. They began on the 15th October (i.e., slightly before the thermocline breakdown, Fig. 1) and ended 41 (1992) and 50 (1993) days later. Each experiment consisted of two treatments (12 tanks per treatment; one female of Eupolymnia nebulosa per tank) which were carried out under the same rearing conditions except for temperature. (1) High, constant temperature treatment 
(HT) was a simulation of a delay in the thermocline breakdown. Water temperature was artificially maintained at $20 \pm 1^{\circ} \mathrm{C}$ by means of a thermostat before distribution into the tanks. (2) Environmental temperature treatment (ET) followed directly the environmental decrease of temperature $\left(17-14.5^{\circ} \mathrm{C}\right.$ in $1992,17-14.7^{\circ} \mathrm{C}$ in 1993). All remaining environmental variables (viz. photoperiod, water renewal) were not controlled during the experiments, but their homogeneity was considered during the experimental design, and checked prior the onset of the experiments.

The adult, mature females of Eupolymnia nebulosa were collected by diving at 5 to 10 $\mathrm{m}$ depth on the sea shore of the Bay of Banyuls, just before starting the experiments. During the course of the experiments, females were maintained in open system tanks with filtered, running seawater (mean flow, $3.23 \pm 0.48 \mathrm{ml} / \mathrm{s}$; tank volume, 2 1). Each tank was supplied once a week with $5 \mathrm{mg}$ of TETRA ${ }^{\complement}$ food $(4.59 \mathrm{cal} / \mathrm{mg}$ of caloric equivalent) mixed with sea water. Only females looking healthy at the end of the experiments were used for subsequent computations (26 from a total of 48, 12 from ET and 14 of HT conditions).

Before oocyte measurements, females were gently anaesthetized with MS-222. Representatives of all categories of coelomic oocytes were obtained from a small portion of female's posterior end (separated from the rest of the body by provoking autotomization). In this way, females were not excessively disturbed, allowing us to obtain comparable measures from the same individuals both at the beginning and at the end of the experiments. We estimated the equivalent spherical diameters (ESD) of a minimum of 300 oocytes of each female to figure oocyte size following Martin et al. (1996).

The ESD were first used to draw the oocyte size distributions (size class intervals of 20 $\mu \mathrm{m})$ of each studied female (i.e., "total" oocyte size distributions). Then, we estimated a data set, which will be referred to as "total" data (viz., mean oocyte size, coefficient of variation, oocyte growth rate, decrease of oocyte size distribution pattern). Oocyte growth rate (GR) and the decrease of oocyte size distribution pattern $(\Delta \mathrm{SD})$ (i.e., changes in dispersion of size class distribution), were calculated as follows:

$$
\begin{gathered}
\mathrm{MS}_{\mathrm{E}}-\mathrm{MS}_{\mathrm{B}} \\
\mathrm{GR}=------ \text { and } \Delta \mathrm{SD}=\mathrm{CV}_{\mathrm{B}}-\mathrm{CV}_{\mathrm{E}}
\end{gathered}
$$

d

where MS is the mean oocyte size and CV is the coefficient of variation, respectively at the beginning (B) and the end $(\mathrm{E})$; $d$ is the duration of the experiments in days. 
During the course of the experiments, only a fraction of the initial oocyte population effectively grew. This fraction was thus estimated to draw the "net" oocyte size distribution of each studied female (size class intervals of $20 \mu \mathrm{m}$ ). We extract "net" oocyte size distributions from the respective "total" distributions by obtaining:

fi - fi' and fi' - fi

where fi and fi' were the frequencies in the ith size-class of the "total" oocyte size distributions at the beginning and at the end, respectively. The absolute values of (fi - fi') and (fi' - fi) represent the "net" frequencies in the ith size-class of "net" oocyte size distributions at the beginning and at the end, respectively. The associated "net" parameters (viz. mean oocyte size, coefficient of variation, oocyte growth rate) were therefore calculated.

The effect of year of experiment (1992 vs. 1993) on all studied parameters was tested by one-way analysis of variance (ANOVA). Since there were no significant effects (Table 1), both experiments were considered together for further computations.

To demonstrate the effect of temperature on oocyte growth, we developed a two-phases analytical procedure consisting of an initial approach to the population level, followed by an approach to the individual level. At a population level, we tested: (1) the differences in mean oocyte size and coefficient of variation between time (beginning vs. end) and temperature conditions (HT vs. ET) by two-way ANOVA and Tukey HSD multiple comparisons test (Underwood 1981); (2) the effect of temperature conditions (HT vs. ET) on oocyte growth rate and the decrease in oocyte size distribution pattern by one-way ANOVA; (3) the differences between the regressions of oocyte growth rates rate and the decrease in oocyte size distribution pattern vs. initial mean oocyte size at HT and ET by analysis of covariance (ANCOVA). Then, we addressed our analytical methods to the finding of ET and HT females with comparable "net" oocyte size distributions. At the individual level, we thus tested the similarity of "net" oocyte size distributions from all HT and ET females by Pearson correlation analysis (Zar 1984), looking for non significantly different females at the beginning that significantly differed at the end. Finally, the significance of the differences in "net" oocyte growth rates from the chosen HT and ET females was tested by Wilcoxon signed rank test (Siegel and Castellan 1988).

We performed the statistical analyses by means of the SYSTAT software (version 5.2.1, copyright (C) SYSTAT Inc. 1990-92). All data were log-transformed, and the required assumptions for parametric tests proved prior the statistical analyses. 


\section{Results}

Population level: "Total" oocyte growth

The initial oocyte size distributions showed a high variability between individuals. We found both dispersed distributions including relatively large oocytes and distributions with very narrow patterns including mainly small gametes. The final oocyte size distributions, however, showed all narrow patterns.

The average values of the "total" data at the different times and temperature conditions are summarised in Table 2. "Total" mean oocyte size was significantly higher at the end (Fratio $=19.15 ; \mathrm{p}<0.001)$ but did not differ significantly between temperature conditions. "Total" coefficient of variation showed a significant effect of time (F-ratio $=94.65, \mathrm{p}<$ 0.001) but also showed a significant combined effect of time vs. temperature conditions (Fratio $=4.28, \mathrm{p}=0.043)$. Based on the ANOVA model $(\mathrm{MSE}=0.115, \mathrm{DF}=43)$, the Tukey test revealed that: (1) size distributions were significantly less dispersed at the end $(\mathrm{p}=$ 0.002), independently of temperature conditions; (2) size distributions of females reared under ET conditions are less dispersed than those of females reared under HT conditions $(\mathrm{p}<0.01)$. "Total" oocyte growth rate and the "total" decrease of oocyte size distribution pattern did not differ significantly between temperature conditions.

"Total" growth rates (TGR) and the respective "total" mean sizes at the beginning $\left(\mathrm{TMS}_{\mathrm{B}}\right)$ were significantly correlated at both temperature conditions. However, neither the slopes nor the interceptions of the obtained regression lines differ significantly. Therefore, the relationship was described by a single equation combining both ET and HT data:

TGR $=2.639-0.015 \mathrm{TMS}_{\mathrm{B}}, \mathrm{r}=0.915, \mathrm{p}<0.001$

Conversely, the relationship between the "total" decrease of oocyte size distribution pattern $(\Delta \mathrm{SD})$ and the respective "total" mean oocyte sizes at the beginning was only significant at ET (Fig. 2A):

$$
\Delta \mathrm{SD}_{\mathrm{ET}}=51.768-0.279 \mathrm{TMS}_{\mathrm{B}}, \mathrm{r}=0.665, \mathrm{p}=0.018
$$

Population level: "Net" oocyte growth 
Since "net" data actually included the oocytes that grew during the experimental period (see Fig. 4 for examples), all analyses were repeated on the "net" data set. The average values of the "net" data at the different times and temperature conditions are summarised in Table 2.

Only time (beginning vs. end) showed significant differences, either analyzing "net" mean oocyte size $($ F-ratio $=55.57 ; \mathrm{p}<0.001)$ or "net" coefficient of variation (F-ratio $=$ 95.09; $\mathrm{p}<0.001)$, these differences being comparatively more marked than those found using "total" data (Table 2). As with "total" data, "net" oocyte growth rate (NGR) did not differ significantly between temperature conditions, whereas a highly significant correlation between this parameter and the respective "net" mean oocyte sizes at the beginning $\left(\mathrm{NMS}_{\mathrm{B}}\right)$ was found for both temperature conditions. Furthermore, neither the slopes nor the intersections of the obtained regression lines differ significantly. Therefore, the relationship was described by a single equation combining both ET and HT data (Fig. 2B):

$$
\mathrm{NGR}=3.017-0.015 \mathrm{NMS}_{\mathrm{B}}, \mathrm{r}=0.848, \mathrm{p}<0.001
$$

Individual level: Comparisons between "net" oocyte size distributions

The significant relationships between initial "net" mean oocyte size and "net" oocyte growth rates prevented us from carrying out direct comparisons between ET and HT females. There were 168 possible combinations of initial "net" oocyte size distributions (i.e., 12 from ET vs. 14 from HT). Pearson correlation analysis pointed out that: (1) 81 of the possible initial combinations were non significantly different ( $\mathrm{p}<0.05$ ) (Fig. 3A); (2) 36 of the corresponding combinations of final "net" oocyte size distributions were significantly different ( $p>0.05)$ (Fig. 3B). 72.2\% of the selected 36 combinations showed HT growth rates higher than those at ET, the average difference in oocyte growth rate favourable to HT females being of $0.0045 \pm 0.0024 \mu \mathrm{m} \mathrm{ESD/day}$. This pattern proved to be highly significant ( $\mathrm{z}$ $=2.97, \mathrm{p}=0.003)$.

\section{Discussion and conclusions}

Differences in overall oocyte growth rates may occur among females from a given population, but also among the oocytes of a single female (Olive 1980). As oogenesis in Eupolymnia nebulosa extends up to, and probably through, the spawning period, the oocytes can be 
released into the coelom at different times. Furthermore, oocyte growth rates vary during the course of the coelomic development, giving rise to effective differences among sizes. This implies that, at any given moment, several oocytes have already reached the maximal size having, from then on, low or even no growth. Therefore, we expected some categories of oocytes to be equally represented both at the beginning and at the end of our experiment. This zero-growth fraction will necessarily disturb growth estimates. Accordingly, we have tried to avoid this difficulty using the "net" data (i.e., the growing oocyte fraction). However, our results point out that, even though growing fractions actively contributed to the changes in size-class distributions, the final appearance of the oocyte size distributions results from the combination of "net" growth with the presence in the coelom of the large zero-growth oocytes.

On the other hand, we have found different growth rates related to the mean oocyte size of females at the beginning of the experiment, even when using "net" data. This fact prevented us from indiscriminately comparing oocyte size distributions among all the studied females. Furthermore, it means that the absence of overall significant differences between HT and ET experimental conditions (i.e., at the population level) can be related to a masking effect owing to the high inter-individual variability, linked to the respective differential growth rates. Since growth rates depend on the oocyte size at the beginning of the experiment, to compare distributions at the end necessarily required the finding of non different (statistically) initial distributions.

Although oocytes grew under the two experimental temperature conditions, our approach allows us to draw two main inferences. (1) An effect of temperature on oocyte growth could not be detected at a population level, but (2) a positive response to the maintenance of a high temperature can be demonstrated by comparing individuals. Rather than to an external factor like temperature, the absence of differences in the effect of the experimental conditions at a population level could be more likely related to: (1) a relationship between differential growth rates and an endogenous factor(e.g., the beginning of oogenesis linked to the shape of oocyte growth rate curves); (2) an unknown exogenous variable (such as photoperiod). However, the lack of a significant response by the population does not imply the absence of any response by individuals.

Two models of interaction between temperature and oocyte growth have been considered in the literature, showing either positive or negative correlation (Olive 1980). In the former case, the greatest degree of synchronization should be expected by the beginning 
of the spawning period when oocyte growth started at times of rising temperature. In the latter, a similar synchronization effect should occur when oocyte growth started at times of declining temperature. However, in light of our results, such simple "rate effects" cannot explain the decrease in size-class diversity observed in Eupolymnia nebulosa. Synchronisation has been observed among females reared under ET conditions, whereas the artificially imposed HT conditions seemed to disturb the normal progress of oocyte growth. Although this response could be interpreted as an adaptation to the habitual environmental conditions of the area, a significant increase of growth rates in individuals reared at HT conditions has been identified. Two more points emerged that disturb the matching of our results with the above theoretical model. (1) After the experimental period, oogenesis and oocyte growth probably continues until May, thus also occurs at times of rising temperature. (2) Oocyte size distributions at the onset of the spawning period are usually highly dispersed, not only at the individual level (authors' unpublished observations), but also at the population level (Bhaud and Grémare 1991).

From all these points, and assuming a sigmoid growth curve (Clark 1965; Bhaud and Gruet 1984; Fischer 1984), we propose a model of Eupolymnia nebulosa oocyte growth interacting with temperature (Fig. 4). The beginning of our experiment (time "a") did not quite coincide with that of gametogenesis. Thus, we would expect a large range of oocyte sizes to be found in the coelom. Before time "a", oocytes grow quickly because, although it is decreasing, the temperature is still high. After time "a", some of these oocytes have already reached their maximal sizes. This fact, together with the rapid decline of temperature, causes this cohort to exhibit decreasing growth rates (possibly dawn to zero). The remaining oocytes, successively produced before time "a", are at different growth stages (their growth being, actually, what we have defined as "net" growth). Therefore, the resulting size distributions at time "a" show a dispersed appearance. The reduction in oocyte size distribution pattern at the end of the experimental period (time "b") results from the combination of: (1) the differential growth rates of the first oocytes produced (wave "F"); and (2) the decrease or even the absence of new oocytes being released to the coelom, this being ????? because the decline of temperature affects the initial stages of oogenesis. Soon after time "b", temperature will rise and production of new oocytes will start again (wave "M"). During the spawning period (from times "c" to "d"), size distributions will show dispersed appearance as a result of: (1) the different growth rates of the successively produced oocytes, and (2) the fact that some large, mature oocytes ready to be spawned have not yet been spawned. 
This model lead us to an apparently contradictory finding. Both mean size and the relative percentage of mature oocytes appear to be higher at the end of the experimental period (time "b") than at the beginning of the spawning period (time "c") (Fig. 4). However, the number of mature oocytes at time "c" should logically be higher than that found at time "b" (i.e., simply due to the accumulation of successive production). This accumulation could only be detected from the absolute number of coelomic oocytes while, as a consequence of our method, we must use relative percentages. To estimate the number, females must be sacrificed. Obviously, sacrificed individuals could not be followed through time, which was at the basis of our experimental design.

Some of the last produced oocytes (wave "L") may not grow fast enough to reach maturity before time "d". These oocytes will remain inside the coelom after the spawning period, probably being used through metabolic ways (i.e., oosorption) as occurs after failure to release eggs in Nephtys hombergii and Eulalia viridis (Olive et al. 1981). The presence of large mature oocytes that are not released (before, during and after the spawning period), supports the rejection of size as a triggering factor for spawning. The existence of a sizedependent mechanism to select "ripe" eggs from an heterogeneous pool in the coelom has been suggested for terebellid polychaetes, such as Amphitrite sp. (Scott 1911) and Eupolymnia nebulosa (Bhaud and Grémare 1991; Martin et al. 1996). However, it would appear that oocyte size does not control the onset of spawning since, if it did, there would be a steady dribbling out of oocytes according to the proposed model. There must therefore be further regulation during the last stages of the oocyte growth and maturation process. Three possible sources of control may be distinguished: (1) cellular mechanisms designating mature (i.e., spawnable) as opposed to immature (i.e., not spawnable) oocytes (see Bentley \& Pacey 1992); (2) mechanical factors related with a limit to space available for the accumulation of oocytes inside the coelom (Olive 1971, 1973); (3) environmental inputs (viz., temperature, light, food).

Although temperature can cause an advancement of the reproductive period as a result of individuals' response, other environmental factors may well act as triggering cues for Eupolymnia nebulosa spawning. (1) The lunar cycle (see Pearse 1990 for a review): a coincidence of the highest spawning peak and the last quarter of the moon in April has been repeatedly observed in the Bay of Banyuls (Bhaud and Grémare 1991). (2) The day length, which could be the basis for matching this particular event into the calendar (Garwood and Olive 1982 for Harmothoe imbricata; Olive 1980 for Nereis pelagica and Nereis diversicolor; 
Olive and Pillai 1983 for Keffersteinia cirrata, Olive, personal communication for Nereis virens). Our experimental period coincides with the decline of temperature but also with a decreasing photoperiod. Although the experimental design allowed us to overcome this last variable, further studies are needed to ascertain which of these two environmental signals have a direct effect in initiating the processes.

As a result of major climatic changes such as global warming (Houghton 1991; Kerr 1991), considerable changes both in distribution patterns (Grainger 1992) and seasonal trends (Olive et al. 1990) of some invertebrate species may be expected. Eupolymnia nebulosa would not be an exception. The capability of this species to release more planktonic, dispersive larvae depends on the placement of the spawning period on the calendar (Duchêne and Nozais 1992). An increase of temperature affecting oocyte growth rates could cause an advancement of spawning. As a consequence of such an advancement, the present course of recruitment, colonization and genetic exchange processes would be disturbed thus, finally, affecting the specific level.

Acknowledgements. We are indebted to P.J.W. Olive and R. Strathmann who kindly discussed our approach and the consequences of our results, subsequently giving helpful scientific comments and highly improving the English language. We also would like to thank the lecturers and the students of the International Advanced Course on Polychaete Autoecology hold in Ischia, Italy (M.C. Gambi and K. Fauchald, organizers) within which substantial discussions were carried out and interesting contributions suggested. This paper is a contribution to the French National Program on Recruitment Determinants (P.N.D.R. G.L.O.B.E.C.) and to the research project AMB94-0746 of the C.I.C.Y.T. of Spain. First and third authors were supported by grants of the C.N.R.S. and I.F.R.E.M.E.R. of France. Second author was benefited by a fellowship of the M.E.C. of Spain (ref. fr93 46037786) and a research contract of the C.S.I.C. of Spain. 


\section{References}

Barnes H (1975) Reproductive rhythms in some marine invertebrates: an introduction. Publ Statz Zool Napoli 39: $1-25$

Bentley MG, Pacey AA (1992) Physiological and environmental control of reproduction in Polychaetes. Oceanogr Mar Biol Annu Rev 30: 443-481

Bhaud M, Cha J-H, Duchêne J-C, Martin D, Nozais C (1995) Larval biology and benthic recruitment: New prospects on the role of egg-masses and proposal on regulation model of the life cycle. Sci Mar 59 (Suppl. 2): 000-000

Bhaud M, Cha J-H, Duchêne J-C, Nozais C (1994). Influence of temperature on the marine fauna: what can be expected from a climatic change. J Therm Biol 20: 91-104

Bhaud M, Grémare A (1991) Reproductive cycle of Eupolymnia nebulosa (Polychaeta, Terebellidae) in the Western Mediterranean Sea. Proc. 2nd Int. Polychaete Conf., Ophelia Suppl. 5, p. 295-304

Bhaud M, Gruet I (1984) Seasonal variation of number and size of oocytes in Sabellaria alveolata (Linné) (Polychaeta; Sabellariidae) and effects of climatic parameters. In: Hutchings PA (ed) Proceedings of the First International Polychaete Conference. The Linnean Society of New South Wales, Sydney, p. 450-460

Boero F, Belmonte G, Fanelli G, Piraino S, Rubino F (1996) The continuity of living matter and the discontinuity of its constituents: do plankton and benthos really exists? Trend in Ecology and Evolution 11: $177-180$.

Clark RB (1965) Endocrinology and the reproductive biology of polychaetes. Oceanogr Mar Biol Ann Rev 3: 211-255

Duchêne JC, Nozais C (1992) Etude de l'émission des stades larvaires précoces d'Eupolymnia nebulosa (Polychaeta: Terebellidae). In, IIIe Colloque du Programme National sur le Déterminisme du Recrutement, edited by P. Nival, J. Boucher, \& M. Bhaud. Ann Inst Océanogr 68: 15-24

Fischer A (1984) Control of oocyte differentiation in nereids (Annelida, Polychaeta) - facts and ideas. In: Fischer A, Pfannenstiel H-D (eds) Polychaete reproduction. Progress in comparative reproductive biology. Gustav Fischer Verlag, Stuttgart, p. 227-245

Garwood PR, Olive PJW (1982) The influence of photoperiod on oocyte growth and its role in the control of the reproductive cycle of the polychaete Harmothoe imbricata (L.). Int J Invertebr Reprod Dev 5: 161-165

Giese JR (1959) Comparative physiology: animal reproductive cycles of marine invertebrates. Ann Rev Physiol 21: $547-576$

Grainger JNR (1992) The probable effects of climate change on invertebrate growth and reproduction with particular reference to Ireland. Invertebr Reprod Dev 22: 239-244

Grémare A (1988) Aspects quantitatifs de la reproduction chez quelques annelides polychètes: interêts et perspectives. Tome 1. Doctoral Thesis, Univ. P. et M. Curie (Paris VI)

Houghton JT (1991) Scientific assessment of climate change: Summary of the IPCC Working Group 1 Report. Proceedings of the Second World Climate Conference. p. 23-24

Kerr RA (1991) Warmth, chill may follow. Science 255: 281 
Martin, D., J.-H. Cha, M. Bhaud. (1996). Consequences of oocyte form modifications in Eupolymnia nebulosa (Annelida, Polychaeta). Invert Reprod Develop 29: 27-36

Olive PJW (1971) Ovary structure and oogenesis in Cirratulus cirratus (Polychaeta, Cirratulidae). Gen Comp Endocrinol 20: 1-15

Olive PJW (1973) The regulation of ovary function in Cirratulus cirratus (Polychaeta). Mar Biol 8: 243-260

Olive PJW (1980) Environmental control of reproduction in Polychaeta: Experimental studies of littoral species in Northeast England. In: Clark WH, Adams TS (eds) Advances in Invertebrate Reproduction, Elsevier Science, Amsterdam, p. 37-51

Olive PJW (1992) The adaptive significance of seasonal reproduction in marine invertebrates: the importance of distinguishing between models. Invertebr Reprod Dev 22: 165-174

Olive PJW, Clark S, Lawrence A (1990) Global warming and seasonal reproduction: perception and transduction of environmental signals. In: Hoshi O, Yamashita $\mathrm{O}$ (eds) Advances in Invertebrate Reproduction. Elsevier Science, Amsterdam, p. 265-272

Olive PJW, Garwood PR, Bentley MG (1981) Oosorption and reproductive failure in Polychaeta in relation to their reproductive strategy. Bull Soc Zool Fr 106: 263-268

Olive PJW, Pillai G (1983) Reproductive biology of the polychaete Kefersteinia cirrata Keferstein (Hesionidae). II. The gametogenic cycle and evidence for photoperiodic control of oogenesis. Int J Invertebr Reprod 6: 307-315

Pearse JS (1990) Lunar reproductive rhythms in marine invertebrates: maximizing fertilization? In: Hoshi O, Yamashita O (eds) Advances in Invertebrate Reproduction. Elsevier Science, Amsterdam, p. 311-316

Precth H, Christophersen J, Hensel H, Larcher W (1973) Temperature and life. Springer, Berlin

Scott JW (1911) Further experiments on the methods of egg laying in Amphitrite. Biol Bull mar biol Lab, Woods

Hole 25: 252-265

Siegel S, Castellan Jr NJ (1988) Non parametric statistics for the behavioural sciences. MacGraw Hill Int., Singapore

Underwood AJ (1981) Techniques of analysis of variance in experimental marine biology and ecology.

Oceanogr. Mar Biol Ann Rev 19: 513-605

Zar JH (1984) Biostatistical analysis. Prentice-Hall Inc., Englewood Cliffs, New Jersey 


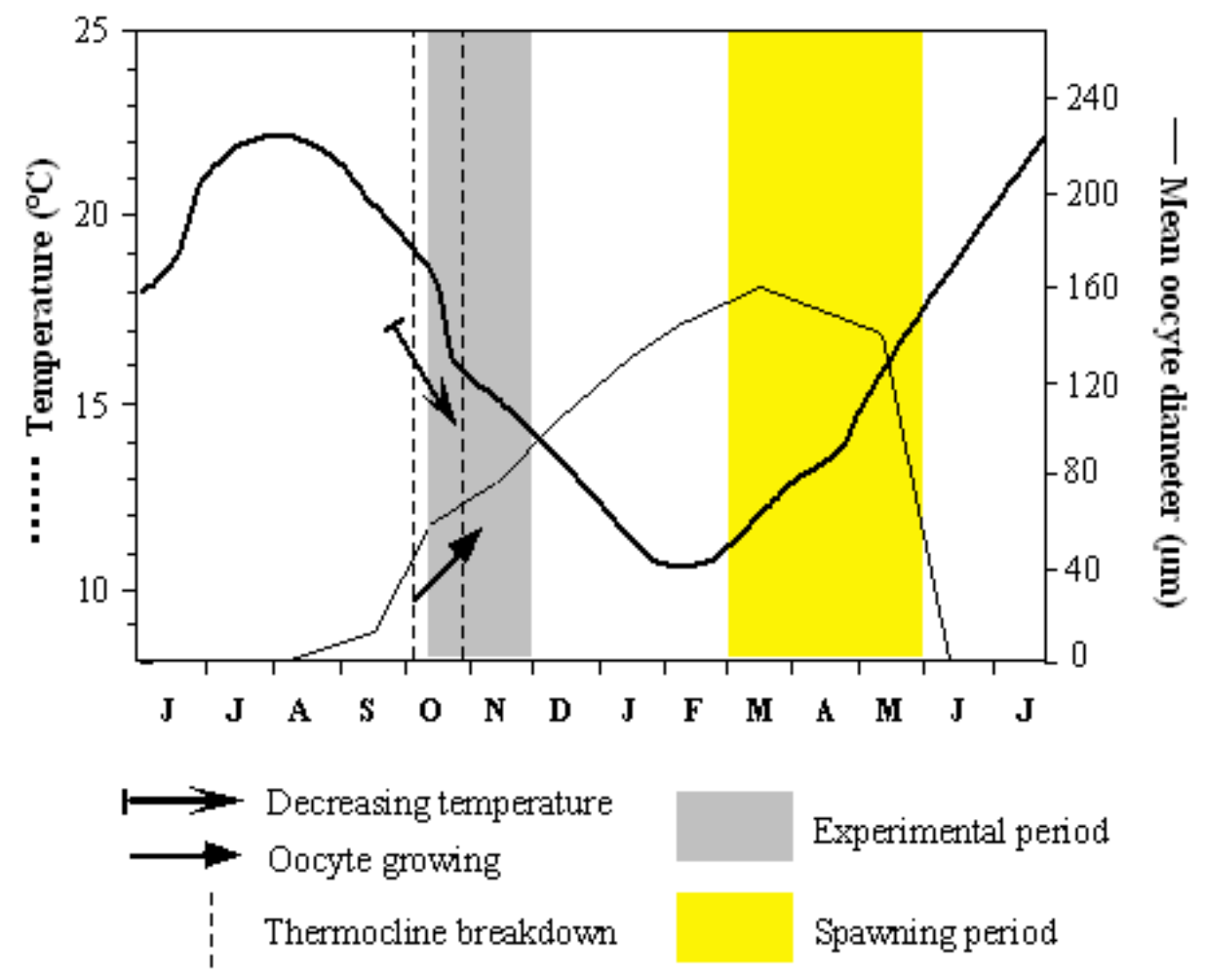

Fig. 1. Eupolymnia nebulosa. Placement of the experimental period on the reproductive cycle of field populations in the Bay of Banyuls (modified from Bhaud and Grémare 1991). The temperature pattern and an approximate location of the thermocline breakdown are also indicated. 

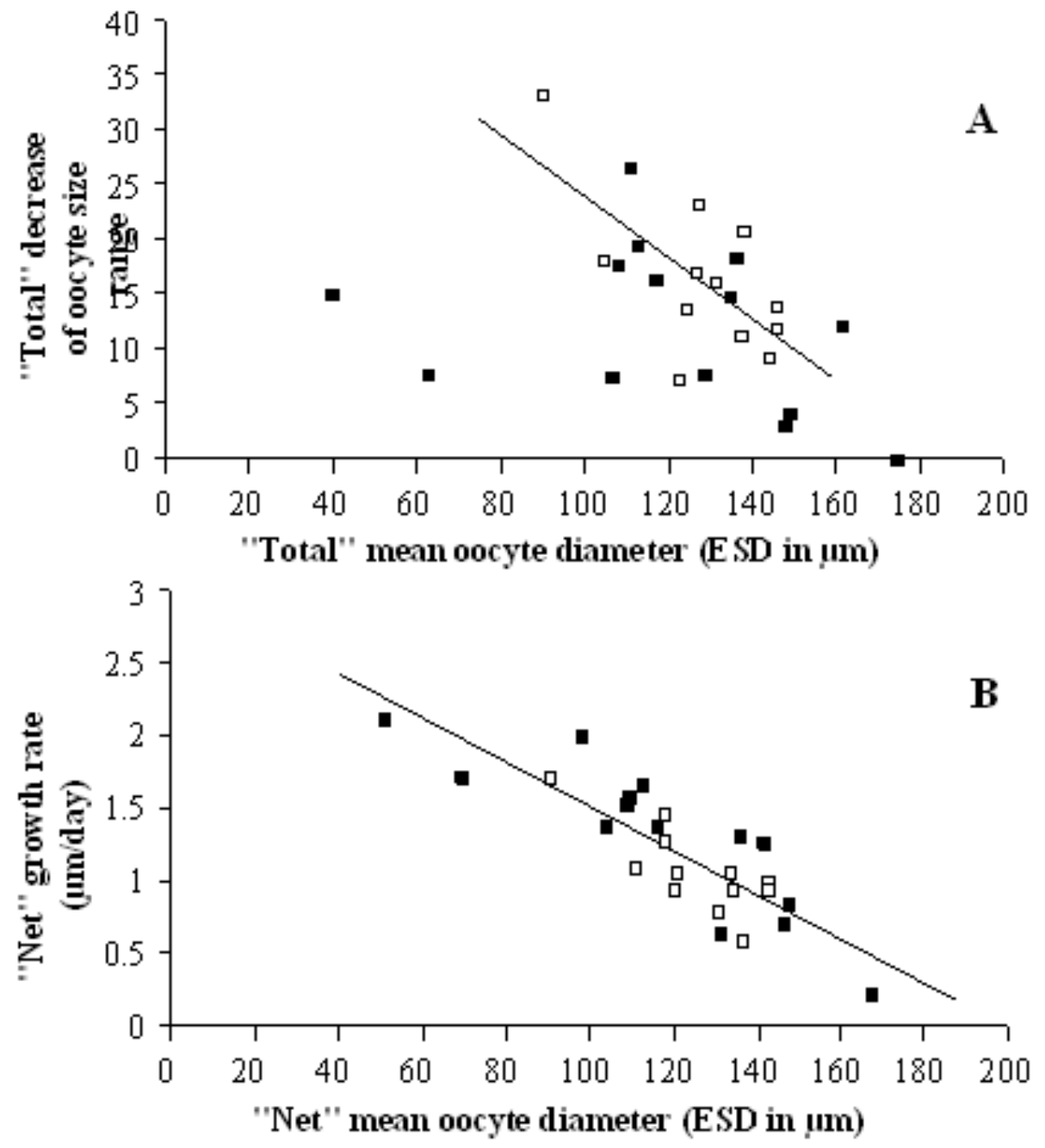

\section{$\mathrm{ET} \quad \mathrm{HT}$}

Fig. 2. Eupolymnia nebulosa. A: Relationship between "total" oocyte mean sizes at the beginning of the experiment and "total" decrease of oocyte size distribution pattern for ET females. B: : Relationship between "net" oocyte mean sizes at the beginning of the experiment and "net" growth rates for both ET and HT females. ET: environmental decreasing temperature. HT: high constant temperature. 


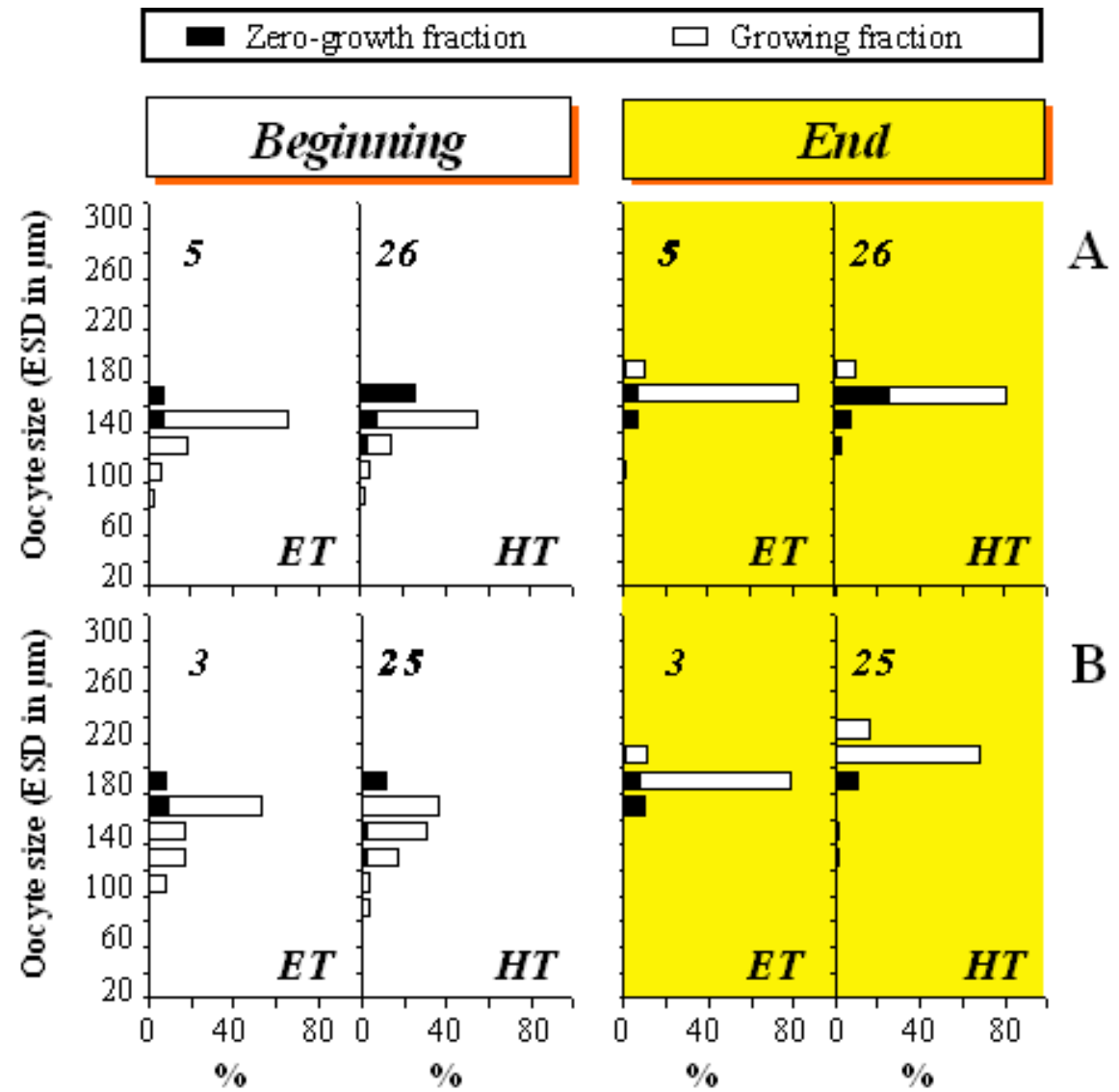

Fig. 3. Eupolymnia nebulosa. Examples of non significantly different pairs of "net" oocyte size distributions at the beginning of the experiment which resulted: (A) not significantly and (B) significantly different at the end (based on Pearson correlation analysis). 


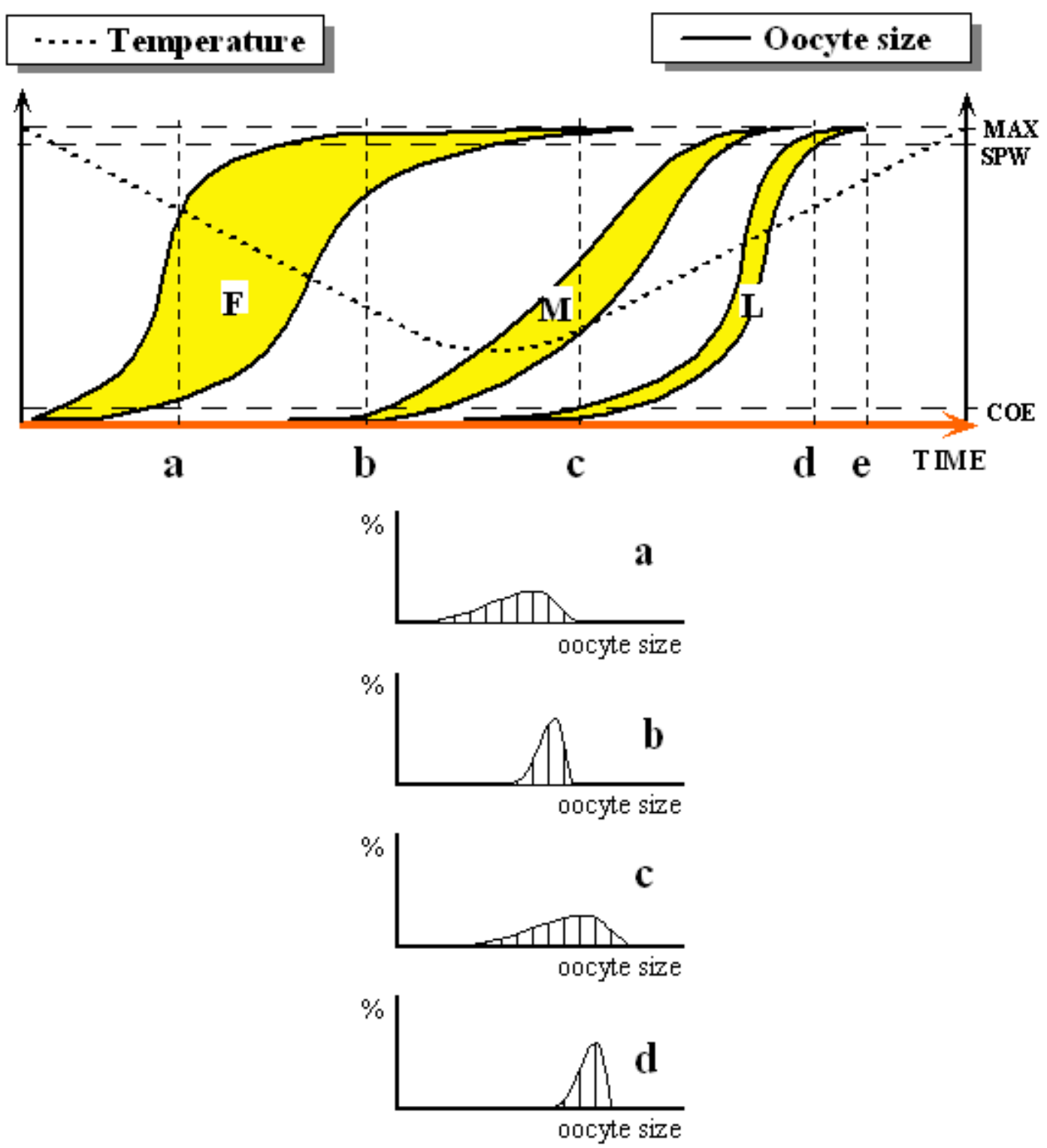

Fig. 4. Eupolymnia nebulosa. Proposal of a model of oocyte growth interacting with temperature. Successive waves of oocyte production: (F) first; (M) an example at the middle; (L) last. Experimental period: from "a" to "b"; Spawning: from "c" to "d"; Oosorption: from "d" to "e". Oocyte size distributions at times "a", "b", "c" and "d" are schematically represented. COE: oocyte size at release to the coelom; SPW: oocyte size at spawning; MAX: oocyte size limit. 
Table 1. Eupolymnia nebulosa. Summary of one-way analyses of variance for the effect of year of experience on the studied parameters. SS: sum of squares; DF: degrees of freedom; MS: mean squares; F-ratio: value of Fisher distribution; p: probability. N.S. means non significant.

\begin{tabular}{lccccc}
\hline Parameters & SS & DF & MS & F-ratio & p \\
\hline Mean oocyte size & 0.096 & 1 & 0.096 & 1.941 & N.S. \\
Coefficient of variation & 0.017 & 1 & 0.017 & 0.109 & N.S. \\
Oocyte growth rate & 0.052 & 1 & 0.052 & 0.212 & N.S. \\
Oocyte size distribution pattern & 1.120 & 1 & 1.120 & 1.930 & N.S. \\
\hline
\end{tabular}


Table 2. Eupolymnia nebulosa. Summary of average values describing oocyte growth during the course of the experiment. Mean Size: mean oocyte size, expressed as equivalent spherical diameter (ESD) length in $\mu \mathrm{m}$; Coeff. Var.: coefficient of variance; Growth rate: oocyte growth rate, expressed as $\mu \mathrm{m} \mathrm{ESD/day;} \mathrm{Distr.} \mathrm{Pattern.:} \mathrm{decrease} \mathrm{of} \mathrm{oocyte} \mathrm{size} \mathrm{distribution}$ pattern; AVG: average; STD: standard deviation. (A) "total" data. (B) "net" data. ET: environmental decreasing temperature (12 females). HT: high constant temperature (14 females).

\begin{tabular}{cccccc}
\hline & & \multicolumn{2}{c}{ Beginning } & \multicolumn{2}{c}{ End } \\
\hline & & AVG & STD & AVG & STD \\
\hline (A) Mean Size & ET & 128.50 & 16.81 & 159.51 & 9.76 \\
& HT & 120.55 & 39.08 & 158.98 & 18.15 \\
Coeff. Var. & ET & 22.63 & 6.49 & 6.67 & 2.44 \\
& HT & 20.18 & 7.08 & 9.48 & 3.40 \\
Growth rate & ET & - & - & 0.621 & 0.294 \\
& HT & - & - & 0.613 & 0.391 \\
Distr. Pattern. & ET & - & - & 16.12 & 7.10 \\
& HT & - & - & 11.99 & 7.44 \\
\cline { 2 - 6 } (B) Mean Size & ET & 125.22 & 14.94 & 173.77 & 11.74 \\
& HT & 117.67 & 31.30 & 174.98 & 16.97 \\
Coeff. Var. & ET & 23.08 & 7.31 & 3.82 & 1.80 \\
& HT & 22.74 & 12.31 & 5.44 & 5.50 \\
Growth rate & ET & - & - & 1.048 & 0.262 \\
& HT & - & - & 1.135 & 0.401 \\
\hline
\end{tabular}

